\title{
11 Enforcing Socioeconomic Rights: Everyday Agency, Resistance and Community Resources among Indonesian Migrant Domestic Workers in Hong Kong
}

\author{
Carol G. S. Tan
}

\section{Introduction}

There are currently over 320,000 full-time, live-in migrant domestic workers (MDWs) in Hong Kong, the vast majority of whom are from Southeast Asia. In recent years, women from the Philippines and Indonesia have constituted 48 per cent and 49 per cent, respectively, of the MDW population, with women from Thailand, Sri Lanka and Nepal making up most of the remainder (Immigration Department 2012). These women and previous generations of women from Southeast Asia account for a significant proportion of the intra-Asia migration of workers, being at the same time a part of the widely observed feminization of migration (see also Elias and Louth, this volume). In the social fabric of Hong Kong, their arrival in ever-increasing numbers, especially since the second half of the 1980s, also marked a sea change in which household chores, child and elder care were commoditized to the extent that in approximately one in eight Hong Kong households an MDW carries out or helps with these tasks.

The nature of domestic work, its private location and the dispersal of its workers, very often as single employees in a household, coalesce to produce a vulnerability that is, in many parts of Asia, worsened by live-in arrangements which may have an impact on access to unions or to help and advice. This vulnerability is why the International Labour Organization has identified women domestic workers as one of the three most vulnerable groups of migrant workers (ILO 2004) and why a Domestic Workers' Convention has now been adopted (ILO number 189). This convention and the longer-standing UN Convention on the Protection of the Rights of All Migrant Workers and Members of their Families (1990) have had some indirect impact in Hong Kong in terms of consciousness raising and lobbying. NGOs and migrant workers' unions, which in Hong Kong are permitted the political space in which to establish themselves and pursue their activities, have invoked both conventions in their ongoing campaigns and, arguably, drawn legitimacy from them 
in fighting two recent major issues: the exclusion of MDWs from the right of abode (akin to permanent residency) (Vallejos and Domingo v Commissioner of Registration 2011) and the exclusion of domestic work from the minimum wage regulations.

These types of high-profile campaigns have often resulted, in Hong Kong and elsewhere, in attention being drawn to the activities of NGOs, unions and human rights activists, with the effect of reinforcing the portrayal of MDWs, along with other female migrant workers, 'as having little or no agency in the world economy' (Ford and Piper 2007: 63). An obvious corrective to this is to examine MDW involvement in collective activism and struggles as Ford and Piper have done. At the level of the individual, ethnographic studies of MDWs have also sought to uncover MDW agency and to do so with fine-grained attention to how individual MDWs view, interpret, respond to and negotiate their subordinate status while often cleverly acting out 'boundary work' as part of the daily performance of their status (Lan 2006; Constable 2007).

A quite different enactment of everyday agency is explored in this chapter namely the role of MDWs as individual litigants seeking compensation from their employer. The research is based upon a number of interviews with Indonesian MDW litigants in Hong Kong. The quite exceptional nature (at least within the context of Asia) of the Hong Kong dispute resolution regime for MDWs is a key factor in enabling migrant workers to sue their employers. However, the examination of these women's experiences points to the very dynamic everyday processes through which MDWs, as a marginalized and economically vulnerable group of actors, are able to access the courts in order to seek redress for a range of injustices. This focus on MDWs as individual litigants seeking justice for themselves (compared to class or representative action) should not be understood in Scott's conception of 'weapons of the weak' not least because, as Piper and Ford and others have pointed out, collective activism and protest is not lacking in Hong Kong (Constable 2010; Hsia 2010). Collective and individual struggles do not, of course, inhabit sealed-off areas that permit no interaction or seepage between the two. One objective of this chapter is also to show how individual MDWs, most likely because of an increase of rights consciousness resulting from collective efforts, are effective interveners in the journeys of other MDWs towards litigation.

It is notable that MDWs as litigants have also been neglected by the scholarship on social and economic rights - an oversight that reflects the general tendency of this literature to treat economic and social rights within the frame of 'citizenship' (specifically the role that constitutionally guaranteed rights can play in generating transformative social change - see also Rosser, this volume). In their work on courts, public policy litigation and economic and social rights, Gauri and Brinks (2008) ask whether courts have been able to effect social transformation by delivering judgements which increase the provision 
of social and economic goods along with the question of whether courts are the correct or better institutions for policy making (see also Gargarella and Domingo 2006). These studies necessarily put courts (especially Supreme Courts or constitutional courts) centre-stage; the litigant is placed somewhat in the wings.

Nonetheless, when Gauri and Brinks turn to mapping the triangle of relationships which connects the state, providers and recipients of socioeconomic rights, they are keen to highlight the sphere of private obligation that connects the providers and recipients of socioeconomic goods - a sphere which has, all too often, been neglected in analyses because of what they characterize as the 'difficult-to-shake background notion that social and economic rights must involve the state' (2008: 11). In this sphere, private enforcement or litigation by the recipient against the provider can, they argue, lead to improved provision of socioeconomic goods. It is perhaps here that we might place the focus of this chapter: MDWs who sue their employers. With some adaptation, their triangle can help us consider the case of MDWs as litigants. MDWs with claims against their employers are seeking labour rights that can be regarded as socioeconomic rights. These rights, in so far as they are embodied in the employment contract between the MDW and her employer, are derived most immediately from private obligations. While the legal framework in Hong Kong would permit state prosecution of employers for failure to provide at least some of those rights, the reality is that enforcement will, to a large extent, rest with the individual MDW as an employee. ${ }^{1}$ Although the Gauri and Brinks triangle offers a place for locating MDWs who sue their employers, an important point of departure from the type of litigation foremost in their minds is that MDWs in Hong Kong who sue their employers are seeking corrective, not distributive, justice. Their aim is not to seek policy changes or novel extensions of existing rights or the recognition of new socioeconomic rights through judicial interpretation. Rather, they are seeking the enforcement of rights already possessed. The importance of studying litigation and other forms of dispute resolution lies in the persistent need to enforce rights by means of seeking corrective justice: it is only through such claims for justice that rights are turned into material compensation for the rights-holder. It is also worth noting that the importance of litigation will only increase with any future enlargement in the socioeconomic rights won by and for MDWs. There is thus no reason to see individual MDW litigation as 'small arms fire' in contrast to the organized 'revolution' of class or representative actions that seek distributive justice. It is appropriate, however, to treat litigation for corrective justice as 'small arms fire' and 'weapons of the weak' in that suing one's employer involves 'everyday' enactments of resistance that arise through processes involving the

${ }^{1}$ In this regard, there is little to differentiate a low-skilled employee from a skilled employee. 
litigant's action or reaction and that of other MDWs acting as individuals, supported by available community and other resources.

Focusing on the contractual character of the relationship between the employer and the MDW can lead us to overlook the fact that these litigants are non-citizens ${ }^{2}$. Theirs is thus a case of non-citizens claiming socioeconomic rights. From the perspective of the general principles of private international law, in particular the question of jurisdiction, MDWs suing their employers is unexceptional because the rules on the jurisdiction of courts usually allow jurisdiction to follow the place of performance of the employment contract. The reality in many Asian MDW destinations, however, is that an MDW dispute with her employer is prohibited from the courts that would be used by non-migrants and instead channelled into a special - though not necessarily specialized - dispute resolution forum. If we take this into account, MDWs litigating in the courts of Hong Kong is exceptional. Moreover, the literature on rights-based approaches to socioeconomic rights presupposes the citizen-state relationship as the main axis for claiming socioeconomic rights (Joshi 2010). From this vantage point too, the fact that non-citizens such as MDWs can enforce their rights in a court is exceptional.

MDWs in Hong Kong have the best terms and conditions in Asia (and probably also in the Middle East). An MDW is legally entitled to a rest day of 24 hours' duration in every seven-day period, statutory holidays, progressive annual leave, adequate food or a food allowance, the cost of travel to her place of origin upon termination of the contract and limits on the deductions that can lawfully be made from her salary. In addition, there is a minimum wage, statutory limits on how much she may be charged for services rendered by the employment agency (EA), and her contract shields her from being asked to work in premises other than the employer's residence. Each contract is of two years' duration and without a probationary period. Both the employer and the MDW may terminate the contract by giving a month's notice. MDWs are also entitled to long-service payments, medical expenses and employment protection for pregnancy and childbirth. These minimum terms and conditions are secured in the three overlapping layers of the contract, employment legislation and labour or immigration department regulations. Moreover, MDWs are supported by aspects of the socio-legal environment in Hong Kong. First, there is a relative absence of extortion and abuse by the personnel of the authorities (police, immigration and labour departments as well as the relevant tribunals). Second, the dispute resolution mechanisms are relatively efficient and are also free to the parties. Third, an active civil society provides a bedrock of resources for the distressed or exploited MDW.

\footnotetext{
2 See also the discussion in Elias and Louth (this volume) regarding the uncertain place of non-citizens in bilateral labour regimes designed to 'protect' migrant domestic workers.
} 
Nevertheless, MDWs do not always receive their contractual dues. Surveys carried out by NGOs show the pattern and frequency of exploitation and abuse (Asian Migrant Centre 2005, 2007; Chiu and Asian Migrant Centre 2005). Moreover, despite reasonable access to justice, those who litigate represent only a small fraction of the MDWs who have experienced sub-contractual and unlawful terms and conditions. The MDW's status, daily experiences and choices are highly constrained, not least by the costs of migration, by the law itself (Tan 2014) and by the sharp practices of some employers (Tan 2000). Low wages, the risk of unemployment, the short two-week window in which they are permitted by the immigration authorities to secure a new employment contract, living in her employer's home and her prohibition against employment pending the conclusion of a claim against her employer constitute basic contours of the constraints against which a decision to sue her employer is taken. For Indonesian MDWs, these constraints are greatly worsened by the state-sanctioned labour migration practices which include high agency fees and long periods in what are officially termed 'training centres', a euphemism for 'labour camps' in which the agencies can 'warehouse labor stock' to meet the vicissitudes of demand for labour (Sim and Wee 2010: 155). These are also places in which the potential migrant worker suffers restrictions on her personal freedom and other forms of coercion. The aim of this chapter is to explore how it is that some MDWs, despite these structural constraints, do end up litigating. What circumstances, factors and conditions account for the MDW 'going to Labour' ${ }^{3}$ and what can we learn about the impediments and challenges MDWs experience along the way which may have prevented others from suing their employers? When the enquiry is directed at the path along which each MDW journeyed or stumbled, the circumstances that triggered the journey, and the various twists and turns along the way, MDWs emerge as actors who draw upon resources available to them.

\section{MDWs 'Going to Labour' in Hong Kong}

In late 2010 and early 2011, interviews with eighteen Indonesian MDWs were carried out. ${ }^{4}$ They were all women who were, at the time, living in one of the several shelters run by Islamic or Christian organizations. Almost all MDWs who spend more than a few days living in a shelter are those whose lives have become entangled in either civil or criminal proceedings. I was interested in how MDWs, in spite of the structural constraints, came to be litigants. The

${ }^{3}$ I use this phrase as an umbrella term to include the initial processes of dispute settlement in the Labour Department as well as the processes at the Labour Tribunal or Minor Employment Claims Adjudication Bureau.

${ }^{4}$ Only a few of the eighteen cases are discussed in this chapter. Interviewees will be referred to using pseudonyms. The interviews were conducted by a native Indonesian speaker. 
main section of the interview asked the open-ended question of how the interviewee came to be in the shelter. The interview also included more closed questions about sources of information and advice that the MDW had received prior to arrival in Hong Kong as well as subsequently. All the women interviewed had a contractual claim pending and, because of this, they had already interacted, to a greater or lesser extent, with legal advisers and legal processes. Their stories thus bore the effects of some of the ordering demanded by legal processes. Most of the women were, for instance, very clear and fluent on the dates of particular events on which their claims were founded and sometimes also fluent in providing explanations for their action or inaction. Some of the women volunteered to be interviewed because it was a chance to practise telling their side of the story. Telling their story without breaking down emotionally, especially if they had been through a harrowing experience, was part of their strategy for seeing their claim to fruition. Despite this filtration process, the women's stories reveal much about MDWs as everyday actors.

In the majority of cases, the women were claiming pay in lieu of the required one month's notice of termination of their contracts; for unpaid wages between termination and their last wage packet; and for the cost of an air ticket and travel expenses from Hong Kong to their place of origin. I refer to these collectively as 'end' rights (i.e., after termination of employment) and contrast them with 'term' rights (i.e., during employment), common elements of which are unpaid wages up to the time when the last monthly wage was paid or ought to have been paid, rest days uncompensated in wages or unlawful wage deductions occurring during employment. MDW claims sometimes include term and end rights although end rights-only cases occur more frequently and there appears to be a correlation between cases including a combination of term and end rights with litigants who can be said to have been prime agents in their own journey towards litigation. Litigants whose claims comprised only end rights, on the other hand, became litigants as a result of the experience of (oftentimes extreme and violent) abuse. This correlation is discussed in the rest of this chapter, in the course of which I also examine the triggers and processes through which MDWs become litigants, emphasizing the everyday processes and networks that are key enabling factors.

\section{The Litigant as a Prime Agent}

A case exemplifying prime agency on the part of the MDW is that of Ina. On a rest day, through a conversation with another MDW 'active in an organization', Ina discovered that her salary was unlawful. She then confronted her employer about her terms and conditions, recording the conversation as had been advised by her fellow MDW. Her employer implied that information on the terms and conditions of employment should have been conveyed by the EA before the 
start of her employment. She then added that the full salary was only for able/ skilled ('pintar') helpers who had four years of previous experience. Ina was still in her first contract in Hong Kong and had, before this contract, never worked as an MDW. She requested a day off some time later, and on that day, accompanied by a friend, she went to Christian Action (one of a small number of legal advice centres) and from there to a shelter. Her claim was for unpaid wages, wages in lieu of rest days and public holidays, as well as wages in lieu of a month's notice, her repatriation costs and salary for the days worked since her last pay packet. Cases such as Ina's, in which the MDW is the prime agent, will often involve term rights as well as end rights. Several aspects of Ina's case are worth noting because they are recurring motifs in the everyday experiences of other MDW litigants.

First, Ina's EA posed a significant obstacle. When Ina went to the EA to retrieve her passport and contract, they refused and only produced the documents when she threatened to call the police. As we shall see, the EA - its proprietor and staff - emerge as a key determinant in whether the MDW becomes a litigant. Second, as we have just seen, Ina invoked the threat of the police. In fact, an MDW who terminates her employment is invariably advised to return to her employer to collect her belongings accompanied by the police (largely to lessen the likelihood of an accusation of theft by the employer). Third, Ina's knowledge and subsequent action were probably delayed because she had been denied rest days until she had worked for several months. Only when she was able to have a rest day was she free to go to Tin Hau (an area frequented by many Indonesian MDWs on their rest days) where she had the critical encounter with an MDW on whose advice she later relied. Rest days create opportunities for extended conversations with other, more experienced MDWs, to pick up a copy of a newspaper, to seek advice before deciding what to do and so forth. Fourth, the likelihood of Ina's claim against her employer succeeding was considerably weakened by the fact that she had signed receipts acknowledging the full salary and rest days. Ina insisted that when she signed the receipts she was told by her employer that these were merely sample documents.

\section{Timing One's Departure from an Employer}

Ina's case is fairly straightforward in the sense that once she was clear that her employer was acting unlawfully, she took action to escape that situation. Her own resolve, combined with the conversation with the more experienced MDW and strengthened by the advice she received at the legal advice centre, led her to become a litigant. Other respondents waited a while before taking action. Nuri explained that she first knew that her salary was an underpayment in her fourth month of work. She had the telephone number of Christian Action because she had been given a newspaper by an acquaintance when she went 
to pick up her employer's child one day. However, she did not dare take action ('tidak berani') because her salary was still subject to a deduction ('masih potongan') of HKD 2,000 per month. In her seventh month of work, she did go to Christian Action where she was advised to collect relevant evidence of her underpayment. Nuri recorded a conversation in which her employer showed her a note signed by Nuri, agreeing to a monthly salary of HKD 2,200 without rest days. The employer reacted angrily at Nuri's queries and threatened to return her to the EA. This threat was in fact carried out but was thwarted by Nuri because en route, with only her mobile telephone and the clothes on her back, she escaped to a shelter, having already been informed about shelters by Christian Action. Nuri's decision to wait until she had repaid her loans is probably not uncommon. Whatever other uncertainties, she had the comfort of knowing that she has no outstanding loans.

The pressure to sit out the period of deductions from her wages to repay loans can be strong enough to persuade an MDW that she should endure several months of very poor conditions such as insufficient sleep, being assaulted by her employer and even being bitten by the employer's dog. Elena recounted how, when she was walking the dog, a friend lent her a newspaper from which she noted the telephone numbers of Christian Action, the Indonesian consulate and the police. Despite this, only in her sixth month did she, on her rest day, find out more from a fellow MDW 'active in an organization' that she should report her conditions to the consulate. Like Nuri, she said that she was too afraid to act before her loans had been repaid.

Some respondents preferred to take action only when they were approaching the end of their contracts. Litigation is risky even when one's case is strong. For many employees including MDWs, litigating is also likely to mean unemployment. On the other hand, if there are term rights involved, the longer an MDW continues to work, the larger the deficit in entitlements will be. Yet, working for longer means having the chance to save up more money which can provide an economic buffer against having no salary while her claim is pending. Furthermore, for the MDWs who take action only towards the end of their two-year contract, the time for looking for a new employer is close at hand and they have probably made up their mind not to seek a further contract with the same employer. The extent to which an MDW feels empowered to finding a new employer is, therefore, important.

In the examples discussed above, the MDW has knowledge that she was being denied a contractual entitlement. She then either leaves her employer, or her employer terminates her employment. The experiences of this group of MDWs suggest that, even where the MDW has been the prime agent in her leap from exploitation to litigation, chance conversations with other MDWs are critical because of the capacity of these contacts to give basic advice on the law and where to find legal advice or refuge. Newspapers, too, are important 
vectors carrying, as they do, telephone numbers that will connect the MDW with the advice centres. The pivotal role played by legal advice centres and shelters is also clear. It is important to note that the MDW is not always in control of the situation, although planning the sequence of her actions with some care may help her to retain control.

\section{End Rights-Only Claims}

An MDW with an end rights-only claim is in a peculiar category because, by definition, she will have no grounds for a claim against her employer until after her employment ended. Her claim is generated by the termination of the contract and the circumstances surrounding it. An MDW running away is not likely to have confronted her employer for her termination benefits and, if dismissed suddenly, is likely to have been evicted without the opportunity to discuss her termination rights.

Two cases will be mentioned briefly. Yuli had suffered assaults by the grandmother in the household soon after she started her contract. She had learnt from the neighbours that her predecessors had experienced the same treatment. She tried to be patient, and when she felt she needed to do something about it, she reported it first to the grandmother's daughter-in-law and later to the grandmother's son. However, the assaults continued and her injuries became unbearable, not least because she was not allowed to seek medical attention. When she could no longer endure the abuse, Yuli sought to terminate the contract, but her employer refused. She then called the police with the result that she was taken to a hospital and eventually to a shelter. Yuli had initiated the termination of the contract but had left without being properly compensated. Having arrived at a shelter with the help of the police, she was only a step away from a legal advice centre where she could be advised on her end-of-contract entitlements. Yuli's case is probably rare in that many MDWs who are physically abused are also those not in receipt of their contractual entitlements, that is, most MDWs who suffer assaults will also have been denied their rights under their contracts. The second case is that of Sari, who reported to the police that she had been repeatedly raped by her employer's husband. She was put in a government-run crisis centre, and her employment was only subsequently terminated. It was this termination that led to Sari bringing a claim for her end-of-contract entitlements.

Far from being of limited value, the end rights-only claims offer significant insights. First, it is precisely because, in most of these end rights-only claims, the MDW flees or is evicted, and, paradoxically, the fact of running away or having been evicted that increases her chances of arriving at a shelter or a legal advice centre. The very acuteness of a woman's situation (as we 
have seen, this includes the cases of physical harm) makes her more likely to be helped at a shelter or advice centre. Second, the circumstances surrounding end rights-only claims suggest that those who have term claims but who are not dismissed suddenly or who do not run away from their employers are less likely to become litigants. Indeed, the majority of women interviewed had end rights-only claims. The overrepresentation of such claims in the face of widespread underpayment of wages and other common breaches of the law suggests that MDWs with term claims are significantly less likely to sue their employers.

\section{Physical Harm as the Trigger for Flight}

Having seen the incidence of assault and rape in Yuli and Sari's experiences in the context of a discussion of the overrepresentation of end rights-only claims, this section looks at two other cases of physical harm that resulted in claims which included term rights. It appears that in these cases the claim came to be made because physical harm caused the MDW to flee. Indeed, most of those interviewed had come to sue their employer because of the experience of physical abuse forcing them to flee - it was only at this critical juncture that they became aware of their legal rights. Both the cases examined next - Maya and Tuti - suggest that were it not for the physical abuse their claims may not have been brought.

Maya's experiences were among the most harrowing of the experiences of those interviewed. She was starved of food and suffered severe mental abuse. She recounted how she had been driven to attempt suicide, but as she was preparing to jump out of the window, her purse fell, scattering photographs of her children. She explained that she was a widow with two sons and a daughter. Her daughter was born only a month after her husband had died. She had decided not to put her daughter up for adoption, resolving to struggle on by herself to educate her children. She recalled her great sadness at that moment when she saw their photographs and realized that she had not been able to send them money. She suggested that she might have persevered if she had been given adequate food. 'How can one work without eating?' she asked. In two months, her weight had decreased from fifty-eight kilograms to fifty-three kilograms. She resolved to run away on her next rest day. She went to Causeway Bay, an area with a high concentration of Indonesian MDWs and which is also the location of the Indonesian Migrant Workers Union (IMWU). Other MDWs, seeing her looking confused, enquired about her circumstances. She did in fact go to IMWU, then to a shelter and then to Christian Action. When she ran away, she had no idea where she should go, let alone have any plan to pursue a claim. She was fleeing the mental abuse, hunger and chronic tiredness. 
Tuti had a claim pending against her employer for unpaid wages, wages in lieu of rest days as well as for her end-of-contract benefits. Similar to Maya, she ran away because of ongoing assaults at her employer's hands and not because she wished to sue her employer. Tuti's employer had told her not to inform the police of the assaults because they would imprison and torture her. She had learnt from the neighbours that the employer had had eleven MDWs from a variety of countries, none of whom had finished their contracts. She remembered the EA's advice to be patient and she did indeed remain with her employer for five months (from May till September) until her employer threatened her with termination without repatriation expenses. While having lunch outside the employer's home the next day, she was asked by an Indonesian MDW why she was so pale. She confided in this fellow MDW, who then offered to take her to a shelter. She left immediately for the shelter and that act brought her employment to an end.

Here again, as we noted with the prime agency cases, the role played by individual MDWs in assisting fellow MDWs cannot be overstated. Some MDWs made enquiries of fellow MDWs when they sensed that something was wrong. More experienced MDWs advised other MDWs on strategy, for example, recording conversations with the employer, and they directed MDWs to shelters or legal advice centres. In other cases, the advice emerged through conversations about salary levels and rest days, including advice to convince the less-experienced MDW that underpayment and the lack of rest days is unlawful. In yet another instance, an MDW gave a fellow MDW the confidence to leave when she explained that her needs would be met at the shelter and that she should not return to her employer. In these ways, the advising MDW acted as a preliminary source of legal advice before the MDW reached a legal advice centre. MDWs also passed round local Indonesian newspapers that publish important telephone numbers and publicize cases of MDWs taking action against their employers. MDWs may also offer assistance in the form of providing temporary shelter, seizing opportunities such as the absence on an overseas trip of an employer (see the case of Dewi, below, and Tan 2014).

The help extended by MDWs also shows how important rest days are for the transmission of advice and comparing notes. Apart from offering respite from the daily grind of menial tasks, rest days are also important because it is then that MDWs with activist or political interests can become involved in NGOs and unions (Nehrling 2010) and, thereby, accumulate the knowledge that enables them to give advice to MDWs facing sub-contractual working conditions. As discussed, quite a few claimant MDWs reported relying on advice from an MDW 'active' in one of the NGOs. On the other hand, so long as an MDW has some opportunity to meet with other MDWs - even fleeting encounters when walking the dog, doing the shopping or collecting the 
employer's children from school - the MDW may still have the opportunity to speak with other MDWs.

\section{Shelters and Legal Advice Centres}

It is very clear from the experiences of the respondents that, if they managed to reach a shelter, the shelter would direct them to the legal advice centre where they would then take steps towards litigation. Because few MDWs in distress go straight to a legal advice centre, shelters act as the most important conduit between the MDW and the legal advice centre. Their importance also lies in the provision of accommodation, food and social activities, all of which help to make suing an employer practicable, given that, in most cases, the litigant is prohibited from taking up other employment. Migrant workers in Hong Kong are comparatively fortunate in having several NGO-run shelters, including some that are run by the organizations that provide active legal advice centres. This means that migrant workers are not solely dependent on their diplomatic missions for safety and refuge or, for that matter, advice and assistance. Given the rise in the view among Indonesian migrant workers that their own government is exploitative rather than ready to assist, the possibility of side-stepping the Indonesian consulate no doubt encourages MDWs to seek redress elsewhere.

As much as shelters efficiently conduct domestic helpers to the legal advice centres, it is the amassed capacity of the legal advice centres that helps the MDWs to navigate the procedures involved in making a claim against her employer. Here the MDW's experience is given its fullest legal potential as her experience is transformed into the paragraphs of her petition. The MDW is given advice on the amount of her claim, the likelihood of success and how long it might take. Paralegal advice centres may also advise the MDW on how to collect evidence before leaving her employer and how to avoid an accusation of theft. It is also the legal advice centres that carry out the role of petition writers by drafting vital letters that the MDW takes to the police, the immigration department, the labour department and to her employer. She is then able to collect her belongings, extend her visa and inform her employer of the action she is taking.

It needs to be stressed that it is often through legal advice centres that the MDW's term claims are conceived. As we have already seen, in a number of cases, the MDW ends up bringing a claim for, say, underpayment over the course of her employment or for wages in lieu of rest days. In some of these cases, it has never really crossed her mind that she could sue her employer for this. In other cases, she may even have known that she was not receiving the contractual wage she had seen in her contract but had not reached the stage of articulating her complaint to her employer or seeking advice. In both these 
scenarios, if not for her arrival at a shelter or legal advice centre, the MDW would probably not have made these term claims.

\section{Employment Agencies}

In contrast to shelters, NGOs and unions, there is almost nothing to suggest that EAs will direct an MDW to the police or to the legal advice centre. EAs have usually colluded in or are aware of the fact that the employer has made unlawful deductions from the MDW's salary or that the MDW has not been paid the minimum wage. The business model of the EA simply does not incentivize them to advise the MDW to sue her employer or to seek help so to do. Instead, it is in their business interest to redeploy an MDW as quickly as possible. Trite as these remarks are, particularly in the current climate in Hong Kong in which EAs have been the target of criticism and campaigns over the high fees they charge MDWs, EAs and their relationships with the MDW and the employer still require some consideration. These relationships are complex and are a feature of the employment of migrant, low-skilled labour and, more specifically, of domestic workers, which is absent in the case of skilled or professional workers.

The relationship between the EA and the MDW is one of some complexity they may be tied by bonds that are financial, involving loans repayable to the EA or its sister company. Other bonds of dependency and trust may arise from the EA being the first port of call for newly arrived MDWs. Many MDWs spend at least a few days at the EA on arrival. This early period at the EA is also where MDWs meet other newly arrived MDWs and have experiences that may shape their expectations in respect of their employment. Ina, for instance, said that she learned from other newly arrived MDWs that they were all expecting a salary of HKD 2,000. She reported that the EA had said little about rest days and salary. Furthermore, the MDW may be able to find temporary accommodation at the agency. EAs may also have staff who are able to speak in Indonesian and who may have kept an eye on new MDWs in the first few days or weeks of their employment, acting as a go-between for the employer and the MDW.

Ina's employer, who is probably not alone among employers to do this, sent her to the premises of the EA on her day off, permitting Ina to spend her rest day only under the supervision of the EA and its staff. Thus, an MDW's relationship with the employer can extend well into the period of the contract of employment. Against this backdrop, it is no surprise that some MDWs should feel that the EA is where they can find shelter as well as, depending on the situation, someone who can intervene in a dispute with the employer. Depending on her work conditions but also on the individual MDW's own social capital, she may have few friends or family to turn to in Hong Kong, though this situation would, for most MDWs, improve with time. There is also the fact that 
agents commonly hold the MDW's passport and other documents. Most of the women interviewed reported that they had to go to the EA to retrieve their passports and contracts after leaving their employers. MDWs such as Dewi also report that they are advised by government authorities to contact the EA if they encounter problems.

First-time MDWs are likely to be more dependent on the EA than more experienced MDWs, and an MDW who is still indebted to an EA will not find it so easy to end her dependency. For some interviewees, the employment agent is where, of their own accord, they turned for help. Dewi, who had suffered repeated minor assaults perpetrated by her employer, contacted her EA when she first ran away from her employer. The EA talked her into returning to her employer. She ran away again seven months later. This time a fellow MDW took Dewi to another EA. She might have stayed there until an employer was found were it not for making three acquaintances there, one of whom had been in Hong Kong for six years and who gave her the telephone number of one of the NGOs. Dewi was soon in the shelter and at a legal advice centre.

For some MDWs, the EA provides them with useful services - for example, a contract with a new employer, the necessary paperwork and repatriation entitlements from the previous employer. Tini, for example, had, through the EAs, completed three contracts. Her fourth contract was terminated early, but she received, through the EA, all that was due to her. That EA had then found her a fifth employer, but this contract was terminated shortly, resulting in Tini being returned to the EA. If not for a conversation with an MDW, who gave her advice to go to a shelter, she might have started a new contract without suing her fifth employer for her end rights. In her case, it was quite natural, given what she had earlier experienced of the EA's services, to trust the EA.

Among other respondents, some either took evasive action to avoid being sent back to the EA or, after being returned to the EA, found a way of escaping. It would appear that, when the trust between the EA and the MDW has broken down, even if the rupture is caused by something trivial, it is more likely that the MDW will end up suing her employer. This is what the experience of Yanti suggests. She had been returned to the EA when her employer became bankrupt. Before sending her to the EA, the employer had provided her with her end benefits. Not many days later the agency found her a new employer with whom she signed a contract. However, before her employment could start, she fell out with the agent over a borrowed umbrella and was ejected from the EA's hostel. Being suddenly homeless, she sought help from a friend and before long found herself successively in the offices of the IMWU, the premises of a Muslim organization, a shelter and then Christian Action. Her subsequent claim against her employer was for wages in lieu of rest days, a matter about which she had never previously confronted her employer. Her 
experience suggests that had the EA not made her homeless, she might have started her new contract without looking back.

Wati is another MDW who may well not have made a claim. She had previously worked for an employer for ten months without her full salary, for very long hours and without all her rest days. At the termination of this contract, she went back to the EA and some weeks later started a new contract. This new contract was fine until, after six months had passed, she was accused of using her male employer's toothbrush. She was then summoned back to the EA, but her female employer explained that this was so that Wati could have a period of 'introspection' rather than because her contract was being terminated. Thereafter, the EA moved her from one place to another and asked her to work for them. Unhappy about this, she ran away to Dompet Dhuafa, an Islamic charity that runs a shelter. In Wati's case, during her six-week stay in Macau to await her visa before taking up her second contract, ${ }^{5}$ she met with an MDW who advised her about her rights and who informed her about Dompet Dhuafa.

The employer's relationship with the EA is also complex. Although, in law, once the employment of the MDW commences, any dispute regarding the employment contract should be a matter between the employer and the MDW, it is common for employers to turn to the EA and, should they wish to terminate an MDW's contract, to 'return' the MDW to the agent. The employer may rely on the EA to take care of the repatriation arrangements and to help them issue written termination agreements for the parties to sign, inform the relevant authorities and so forth. Employers unhappy with the MDW they have been sent and seeking a 'replacement' are very likely to return the MDW to the EA and negotiate a reduced fee for a new MDW. This is a practice that is reinforced by the contract between the employer and the EA. The agency, on the other hand, has an interest in placing the returned MDW with another employer as quickly as possible.

\section{Conclusion}

Some MDWs, despite the multiple structural disadvantages, manage to sue their employers for breaches of their employment contract. The relatively small number of interviews with Indonesian MDWs suggests two main observations regarding who, and in what circumstances and processes, manages to sue. First, few MDWs sue their employers without the aggravating experience of physical violence. It may be inferred that many of those suffering the commonest breaches of contract, such as a lack of rest days or underpayment of

\footnotetext{
${ }^{5}$ For an explanation of why neighbouring Macau has become an 'overflow' area for MDWs out of work in Hong Kong see Sim and Wee (2010).
} 
wages, do not sue their employers. Second, among those who became litigants, few were prime agents in the sense described earlier. If they took the decision to run away, it was to escape physical abuse and not due to any intention, however vague, to seek redress for breaches of their employment contracts.

The women who end up as litigants constitute a minority. Yet, rather than dismissing their experiences on the basis that they have nothing to tell us about the women who do not litigate, their experiences in fact shed much light. They illuminate the interplay between the MDW's personal capital and resolve, events beyond her control, lesser and more significant interventions by others and available resources for help and advice that facilitate litigation. They show that 'labour' is often an unplanned destination; the journey towards litigation is triggered by a dramatic event or an experience of acute stress that ruptures the relationship with her employer. We can infer from this that, in the absence of such an event, MDWs may continue in their contracts without seeking redress, perhaps weighing in the balance also the extent to which they find their employment conditions tolerable, or even satisfactory.

The women's stories also allow us to order by impact several factors. When a dramatic event has occurred, MDWs manage to litigate because of the legal advice centres and shelters that exist in Hong Kong. The experiences of the respondents suggest that few initiate their journey towards litigation without the intervention of others, particularly fellow MDWs. The capacity of Indonesian MDWs to advise and assist one another is clear. It is very likely to be a result of the political and social space which has allowed NGOs attentive to migrant workers to operate, spread their message and help with that capacity building. MDWs as sources of advice are much needed given that a number of MDWs reported that the advice given to them before departing Indonesia was confined to matters more connected with morals, sexual relationships and directed at preparing MDWs to be disciplined workers.

After arrival, there is the role of the free newspapers that circulate among MDWs and which appear to be more effective than the guide books prepared for MDWs by the Hong Kong government agencies or the Indonesian consulate. A number of women reported that their copy of the guide book was confiscated by either the EA or their employer. Some MDWs may be able to conceal the guide book or to persuade her employer that it was 'nothing'. As one MDW commented, a piece of paper with the relevant telephone numbers or addresses is easier to conceal. MDWs are able to sue their employers also because they have been able to count on police assistance at the key moment when they wish to leave their employer's home. Without the police, an MDW would have to rely on the EA and the MDW's respective consular services unless she was able to make contact with a union representative. As discussed above, EAs are inhibitors because it is not in their interests to advise the MDW on her rights against her employer or to point her towards the legal advice centres. Their aim 
is to recycle the MDW into another contract as soon as possible. Only if there is a destabilization of her relationship with the EA will an MDW's chances of becoming a litigant increase. The Indonesian consulate has few defenders when it comes to their record of serving the interests of Indonesian MDWs. In thinking of what action to take, resources we have not examined here include the MDW's experience of work and life and her personal financial situation. Her personal capital no doubt influences the extent to which she is able to exercise agency - be that to act, to resist or to assist an MDW in distress. As a matter of policy, the continued funding of legal advice centres, shelters and proper training of the police (so that they do not send MDWs back to EAs, for example) is vital.

Over and above these particular observations, the stories of the MDWs who litigate destabilize the still dominant portrayal of MDWs in which the language of 'protection' and 'structural constraints' denies them their agency. They also redress the imbalance caused when attention is inevitably drawn to the high-profile campaigns for the improvement of the rights of MDWs in which collective action for or by MDWs is featured. In litigation, we see how some MDWs use the narrowest of opportunities to seek advice or to collect vital evidence with which to overcome earlier detrimental acts such as signing receipts for full wages and rest days. An MDW may initiate a dispute by voicing her complaint to her employer; she may, with the help of other MDWs, calculate when she should run away from her employer; she may have to either resist being sent to the EA or engineer her escape from the EA. In possession of professional advice, she chooses whether or not to proceed with a claim and she finds the courage to attend labour department meetings or tribunal hearings without representation in which her employer will be present. She determines, usually without professional advice, if she should accept an offer to settle. Initiating action or reacting to their circumstances as litigants, we see MDWs as everyday actors who can change the course of their own paths and who can negotiate hurdles and overcome challenges in order to improve their fortunes or avoid further harm.

\section{References}

Asian Migrant Centre (2005) Underpayment: Systematic Extortion of Indonesian Migrant Workers in Hong Kong. www.asian-migrants.org/index.php?option=com_content $\&$ task=view\&id=4\&Itemid $=29$.

(2007) Underpayment 2: The Continuing Systematic Extortion of Indonesian Migrant Workers in Hong Kong. www.ilo.org/jakarta/whatwedo/publications/ WCMS_116888/lang--en/index.htm.

Chiu, S. W. K. and Asian Migrant Centre (2005) A Stranger in the House: Foreign Domestic Helpers in Hong Kong. Hong Kong: Hong Kong Institute of Asia-Pacific Studies. 
Constable, N. (2007) Maid to Order in Hong Kong: Stories of Migrant Workers, 2nd edition. Ithaca: Cornell University.

(2010) 'Migrant workers and the many states of protest in Hong Kong', in N. Constable (ed.) Migrant Workers in Asia: Distant Divides, Intimate Connections. Abingdon: Routledge, pp. 127-144.

Ford, M. and Piper, M. (2007) 'Southern Sites of Female Agency: Informal Regimes and Female Migrant Labour Resistance in East and Southeast Asia', in Hobson, J. M. and Seabrooke, L. (eds.) Everyday Politics of the World Economy. Cambridge: Cambridge University Press, pp. 63-80.

Gargarella, R. and Domingo, P. (2006) Courts and Social Transformation in New Democracies. Aldershot: Ashgate.

Gauri, V. and Brinks, D. M. (2008) 'Introduction: the elements of legalization and the triangular shape of social and economic rights', in V. Gauri and D. M. Brinks (eds.) Courting Social Justice: Judicial Enforcement of Social and Economic Rights in the Developing World. Cambridge: Cambridge University Press, pp. 1-37.

Hsia, H.-C. (2010) 'The making of a transnational grassroots migrant movement: a case study of Hong Kong's Asian migrants' coordinating body', in N. Constable (ed.) Migrant Workers in Asia: Distant Divides, Intimate Connections. Abingdon: Routledge, pp. 105-126.

Immigration Department (2012) Annual Report 2011. www.immd.gov.hk/publications/ a_report_2011/en/foreword/vision.html.

ILO (2004) Towards a Fair Deal for Migrant Workers in the Global Economy. Geneva: International Labour Organization.

Joshi, A. (2010) 'Do rights work? Law, activism and the employment guarantee scheme', World Development 38(4): 620-630.

Lan, P.-C. (2006) Global Cinderellas: Migrant Domestics and Newly Rich Employers in Taiwan. Durham: Duke University Press.

Nehrling, E. (2010) 'Beyond the Right to Rest: An Evaluation of the Social and Legal Structures Shaping the Agency of Foreign Domestic Workers in Singapore', SEARC Working Paper Series, No. 107, City University of Hong Kong.

Sim, A. and Wee, V. (2010) 'Undocumented Indonesian workers in Macau: the human outcome of colluding interests', in N. Constable (ed.) Migrant Workers in Asia: Distant Divides, Intimate Connections. Abingdon: Routledge, pp. 145-163.

Tan, C. G. S. (2000) 'Why rights are not enjoyed: the case of foreign domestic helpers in Hong Kong', Hong Kong Law Journal 30(3): 354-360.

(2014) 'How Dewi Became a Litigant: Migrant Domestic Workers as Litigants in Hong Kong', SEARC Working Paper Series, No 151, City University of Hong Kong. Vallejos Evangeline B v Commissioner of Registration, HCAL 124/2010 (30 September 2011). 